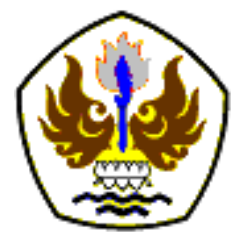

INFOMATEK

Volume 22 Nomor 2 Desember 2020

\title{
ANALISIS DAN PERANCANGAN LOOPS PADA SISTEM PEMIPAAN JALUR PIPA GAS DENGAN MENGGUNAKAN PROGRAM CAESAR II
}

\author{
Insan Kamil Komaruzaman*, Jojo Sumarjo, Aa Santosa \\ Jurusan Teknik Mesin \\ Universitas Singaperbangsa Karawang
}

\begin{abstract}
Abstrak: Sistem pemipaan merupakan berfungsi untuk mengalirkan fluida (Zat cair, gas) dari satu tempat ketempat lainnya bisa dalam bentuk pipeline ataupun piping. Sistem pemipaan harus dirancang sedemikian rupa supaya terhindar dari kecelakaan yang diakibatkan oleh kelebihan beban/Overload maupun kelebihan panas / Overheat. Salah satu cara untuk membuat sistem pemipaan aman, maka dibuat sebuah loops untuk menjaga supaya tidak terjadi expansion thermal. Untuk itu dalam perancangan pipa salah satu yang harus dilakukan adalah analisis tegangan (stress analysis),yang mana harus diupayakan agar tegangan maksimum yang terjadi pada pipa tidak melebihi tegangan izin material yang digunakan dalam perancangan. Dalam Penelitian ini dirancang sebuah loops pada sistem pemipaan untuk mengalirkan gas yang bertemperatur $140^{\circ} \mathrm{F}$ dengan tekanan didalam pipa sebesar 1000 psi, dengan jarak antar reservoir sejauh $1 \mathrm{~km}$ dengan kondisi seperti itu dikhawatirkan akan terjadi bending pada pipa tersebut. Perancangan dan analisis sistem pemipaan ini merujuk kepada Code Asme B31.3 dengan material A-335 P11. Hasil penelitian dengan menggunakan simulasi ini menunjukan bahwa tegangan maksimum yang terjadi pada pipa dengan pressure $100 \mathrm{Psi}$, temperatur $140^{\circ} \mathrm{F}$ sebesar 2025,6 lb/sq.in. Dicplacement (pergerakan) maksimal terjadi pada node 29 sebesar 0,0635 in dalam arah sumbu z. Gaya terbesar terjadi pada node 18 dan 29 searah sumbu y sebesar 3400,6 lb. Nilai tegangan maksimum tersebut masih jauh di bawah tegangan izin materialnya sebesar $30000 \mathrm{lb} / \mathrm{sq}$.in, dan pipa tidak mengalami overstress karena tegangan yang terjadi tidak melebihi tegangan izin maksimum dari meterial pipa, sehingga loops yang direncanakan dikatakan aman.
\end{abstract}

Kata kunci: Loops, Expantion thermal, Sistem pemipaan, Overload, Overheat

\section{PENDAHULUAN}

\subsection{Latar Belakang}

Suatu sistem pemipaan akan mengalami pembebanan pada kondisi oprasi atau tidak beroperasi, beban-beban ini mengakibatkan terjadinya tegangan, seperti tegangan sustain

\footnotetext{
*)komaruzaman23@gmail.com

Pertama diterima: 8 September 2020

Direvisi: 20 November 2020

Disetujui untuk publikasi: 23 November 2020
}

dan tegangan ekspansi (Armansyah dkk. [1]), (ASME [2]). Adapun opsi yang digunakan untuk mengurangi beban ekspansi adalah dengan menambahkan design expansion loops (Lazuardi [3]).

\subsection{Beban Sustain (Sustain Loads)}

Beban sustain adalah beban yang bekerja terus-menerus selama operasi. Beban ini 
merupakan kombinasi beban yang diakibatkan oleh tekanan internal dari fluida yang dialirkan dan beban berat (berat fluida dan berat pipa). [3]. Pada beban sustain terjadi tegangan akibat internal pressure dan tegangan akibat gaya berat sistem perpipaan.

\subsection{Beban Ekspansi Termal (Expansion Load)}

Beban ekspansi merupakan beban yang timbul akibat adanya perpindahan pada struktur pipa (ekspansi termal) pada sistem perpipaan. Beban ekspensi termal dapat dibagi menjadi (Migas Indonesia [4]).

\subsection{Expansion loop}

Expansion loop adalah suatu metoda yang digunakan pada desain sistem perpipaan yang intinya mengurangi tegangan akibat muai dan susut nya si pipa. Muai dan susut semata2 disebabkan oleh 'Perubahan Temperature' dari kondisi ambien ke kondisi operasi (Kannapan [5]).

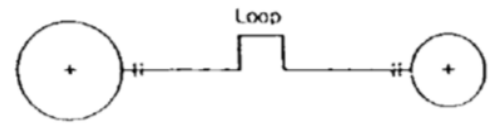

Gambar 1

Bentuk Loop [5]

Ketika terjadi pertambahan beban pada pipa, maka funsi loop disini adalah untuk menjaga supaya tidak terjadi bending secara permanen, loop akan bergerak secara fleksibel sehingga pipa akan aman dari kegagalan.

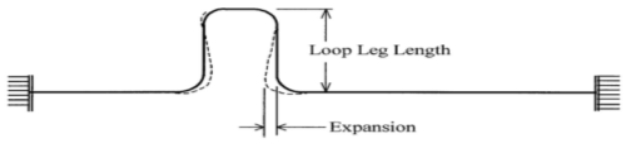

Gambar 2.

Gerakan loop akibat expantion [5]

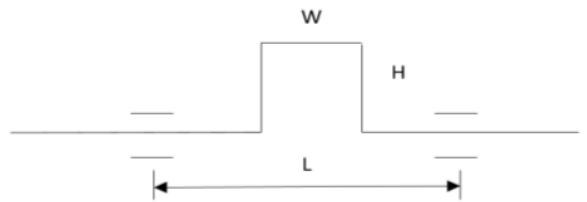

Gambar 3.

Ukuran Loop [5]

Panjang Span (L) bisa dicari berdasarkan defleksi dan stress [5], (Harahap [6]).

$$
\begin{aligned}
& \text { Span } L=\sqrt[2]{\frac{0,4 \cdot Z \cdot S h}{W}} \quad \text { Limited of stress } \\
& \text { Span } L=\sqrt[2]{\frac{\Delta \cdot E \cdot I}{13,5 \cdot W}} \quad \text { Limited of deflection }
\end{aligned}
$$

Langkah berikutnya mencari ukuran tinggi $(\mathrm{H})$ dan lebar (W) Loop

$$
\begin{aligned}
& L 2=\sqrt[2]{\frac{3 E D \Delta}{144 S_{A}} \ldots \ldots \ldots \text { (estimate loop) }} \\
& \mathrm{L} 2=\mathrm{W}+2(\mathrm{H})
\end{aligned}
$$

Mencari $\mathrm{S}_{\mathrm{A}}$ (allow Stress) Tegangan yang diijinkan

$$
\mathrm{S}_{\mathrm{A}}=\mathrm{f}\left(1,25 \mathrm{~S}_{\mathrm{C}}+0,25 \mathrm{~S}_{\mathrm{H}}\right)
$$

\subsection{Caesar II}

Caesar II adalah program komputer untuk perhitungan Stress Analysis yang mampu 
mengakomodasi kebutuhan perhitungan Stress Analysis seperti tegangan yang diakibatkan oleh beban termal atau beban luar. Sofwere ini sangat membantu dalam Engineering terutama desain Mechanical dan sistem perpipaan dengan menggunakan simple beam element kemudian menentukan kondisi pembebanan sesuai dengan mondisi yang dikehendaki. Dengan memberikan/ membuat inputan tersebut Caesar II mampu menghasilkan hasil analisa berupa stress yang terjadi, beban, dan pergeseran terhadap sistem yang kita analisa [5].

\section{METODOLOGI}

Data Penelitian tentang Stress Analysis pada pipa penyalur gas ini merujuk kepada standar Code ASME B31.3.

Tabel 1. Data Penelitian

\begin{tabular}{|l|l|}
\hline DESIGN STANDAR CODE & ASME B31.3 \\
\hline Outside Doameter (Do) & 10 inch \\
\hline Corrosion Allowance & 0,118 inch \\
\hline Design Tempetaur & 140 \\
\hline Internal Design Pressure (Pi) & 1000 Psi \\
\hline Joint Efficiency (E) & 1 (seamless) \\
\hline Desain Safety Factor & 0,3 \\
\hline $\begin{array}{l}\text { Pipeline Material \& Specified } \\
\text { Minimum Yield Strenght }\end{array}$ & 65.000 Psi \\
\hline Modulus elastisitas & $2.07 \mathrm{E}+05$ \\
\hline Desain Factor(F) & 0,72 \\
\hline
\end{tabular}

\section{ANALISIS DAN PEMBAHASAN}

\subsection{Perhitungan Ukuran Loop}

Perhitungan dimulai dengan mencari panjang Span (L) yang diakibatkan oleh tegangan Pers. (1), maka didapat sebesar 9,9 feet. Mencari panjang Span (L) yang diakibatkan oleh Defleksi Pers. (2) maka didapat sebesar 306,49 feet.

Span yang direkomendasikan 9,9 feet (terkecil)

$\mathrm{L}=9,9 \mathrm{ft}=3,5 \mathrm{~m}$

$\mathrm{L}=\mathrm{W}+2(\mathrm{H})$

Sehingga $3,3=1+2(0,75)$

$\mathrm{W}=1$ meter dan $\mathrm{H}=0,75$ meter

Ukuran Loop hasil perhitungan berdasarkan tegangan dapat dilihat pada Gambar 4.

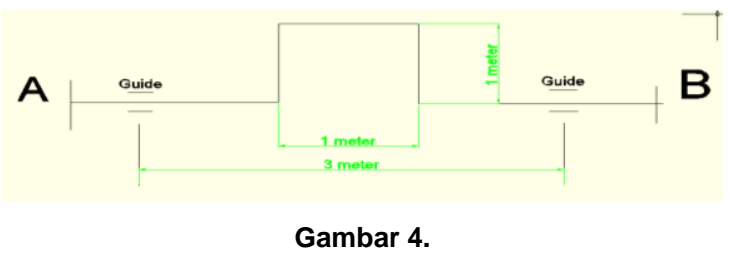

Ukuran Loop hasil perhitungan berdasarkan tegangan.

\subsection{Data Hasil Simulasi dengan Sofwere Caesar II}

Hasil simulasi akibat temperatur dan tekanan pada loop dapat dilihat pada Gambar 5. 


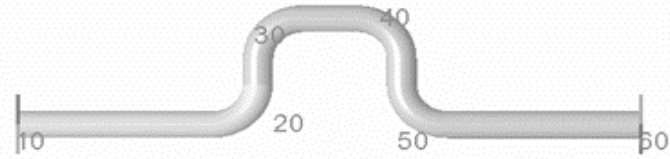

Gambar 5.

Hasil simulasi akibat temperatur dan tekanan pada loop.

Hasil penelitian mengenai pergerakan pipa yang terjadi akibat tekanan dan temperatur dan berat pipa untuk tiap node dapat dilihat pada Tabel 2. Tabel 3 memperlihatkan gayagaya yang terjadi pada tiap node. Sedangkan Tabel 4 memperlihatkan hasil pengukuran mengenai data tegangan yang terjadi pada tiap node akibat temperatur, tekanan dan berat pipa.

Tabel 2. Data pergerakan pipa akibat tekanan dan temperatur, dan berat pipa tiap node

\begin{tabular}{|c|c|c|c|c|c|c|}
\hline Node & DX in. & DY in. & DZ in. & $\begin{array}{c}\text { RX } \\
\text { deg. }\end{array}$ & $\begin{array}{c}\text { RY } \\
\text { deg. }\end{array}$ & $\begin{array}{c}\text { RZ } \\
\text { deg. }\end{array}$ \\
\hline 10 & -0.000 & -0.000 & -0.000 & -0.000 & 0.000 & 0 \\
\hline 18 & 0.027 & -0.000 & -0.027 & -0.000 & 0.050 & 0 \\
\hline 19 & 0.026 & -0.000 & -0.040 & -0.000 & 0.064 & 0 \\
\hline 20 & 0.015 & -0.000 & -0.050 & -0.000 & 0.068 & 0 \\
\hline 28 & 0.003 & -0.000 & -0.054 & -0.000 & 0.065 & 0 \\
\hline 29 & -0.005 & -0.000 & -0.063 & -0.000 & 0.044 & 0 \\
\hline 30 & -0.003 & -0.000 & -0.070 & 0.000 & 0.013 & 0 \\
\hline 38 & 0.003 & -0.000 & -0.070 & 0.000 & -0.013 & 0 \\
\hline 39 & 0.005 & -0.000 & -0.063 & 0.000 & -0.042 & 0 \\
\hline 40 & -0.003 & 0.000 & 0.0547 & 0.000 & -0.065 & 0 \\
\hline 50 & -0.027 & -0.00 & -0.027 & 0.000 & -0.050 & 0 \\
\hline 60 & 0.000 & 0.00 & 0.000 & 0.000 & -0.000 & 0 \\
\hline
\end{tabular}

Tabel 3. Data gaya-gaya yang terjadi tiap node

\begin{tabular}{|c|c|c|c|c|c|c|}
\hline Node & fx lb. & fy lb. & fzlb. & $\begin{array}{c}m x \\
\text { ft.lb. }\end{array}$ & $m x$ ft.lb. & $m z$ ft.lb. \\
\hline 10 & 1860 & 0 & -0 & 0.0 & 0.0 & 2021.5 \\
\hline 18 & 1860 & -0 & -0 & 0.0 & 2021.5 & 0.0 \\
\hline 19 & 1315 & -0 & -1315 & 0.0 & 1340.4 & -0.0 \\
\hline 20 & -0 & 0 & 1860 & -0.0 & 303.8 & -0.0 \\
\hline 28 & -0 & -1860 & 0 & -0.0 & 0.0 & 1756.4 \\
\hline 29 & 1315 & 0 & 1315 & 0.0 & 3400.6 & -0.0 \\
\hline 30 & 1860 & -0 & -0 & -0.0 & -0.0 & -4081.7 \\
\hline 38 & 1860 & -0 & -0 & -0.0 & 4081.7 & -0.0 \\
\hline 39 & 1315 & -0 & -1315 & -0.0 & 3400.6 & -0.0 \\
\hline 40 & 0 & 0 & 1860 & -0.0 & -1756.4 & -0.0 \\
\hline 50 & -1860 & 0 & 0 & -0.0 & -2021.5 & 0.0 \\
\hline 60 & -1860 & -0 & 0 & -0.0 & 0.0 & -2021.5 \\
\hline
\end{tabular}

Tabel 4. Data tegangan yang terjadi tiap node akibat temperatur, tekanan dan berat pipa

\begin{tabular}{|c|c|c|c|c|c|c|c|c|}
\hline Node & $\begin{array}{r}\text { Bending } \\
\text { Stress } \\
\mathrm{lb} . / \mathrm{sq} . \mathrm{in} .\end{array}$ & $\begin{array}{r}\text { Torsion } \\
\text { Stress } \\
\text { |b./sq.in. }\end{array}$ & 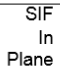 & $\begin{array}{r}\text { SIF } \\
\text { Out } \\
\text { Plane }\end{array}$ & $\begin{array}{r}\text { Code } \\
\text { Stress } \\
\text { lb./sq.in. }\end{array}$ & $\begin{array}{r}\text { Allowable } \\
\text { Stress } \\
\text { lb./sq.in. }\end{array}$ & $\begin{array}{r}\text { Ratio } \\
\%\end{array}$ & $\begin{array}{l}\text { Piping } \\
\text { Code }\end{array}$ \\
\hline 10 & 2025.6 & 0.0 & 1.000 & 1.000 & 2025.6 & 30000.0 & 6.8 & B31.3 \\
\hline 18 & 2025.6 & -0.0 & 1.000 & 1.000 & 2025.6 & 30000.0 & 6.8 & B31.3 \\
\hline 18 & 2025.6 & 0.0 & 1.000 & 1.000 & 2025.6 & 30000.0 & 6.8 & B31.3 \\
\hline 19 & 1343.1 & -0.0 & 1.000 & 1.000 & 1343.1 & 30000.0 & 4.5 & B31.3 \\
\hline 19 & 1343.1 & 0.0 & 1.000 & 1.000 & 1343.1 & 30000.0 & 4.5 & B31.3 \\
\hline 20 & 304.4 & -0.0 & 1.000 & 1.000 & 304.4 & 30000.0 & 1.0 & B31.3 \\
\hline 20 & 304.4 & 0.0 & 1.000 & 1.000 & 304.4 & 30000.0 & 1.0 & B31.3 \\
\hline 28 & 1759.9 & -0.0 & 1.000 & 1.000 & 1759.9 & 30000.0 & 5.9 & B31.3 \\
\hline 28 & 1759.9 & 0.0 & 1.000 & 1.000 & 1759.9 & 30000.0 & 5.9 & B31.3 \\
\hline 29 & 3407.4 & -0.0 & 1.000 & 1.000 & 3407.4 & 30000.0 & 11.4 & B31.3 \\
\hline 29 & 3407.4 & 0.0 & 1.000 & 1.000 & 3407.4 & 30000.0 & 11.4 & B31.3 \\
\hline 30 & 4089.9 & 0.0 & 1.000 & 1.000 & 4089.9 & 30000.0 & 13.6 & B31.3 \\
\hline 30 & 4089.9 & -0.0 & 1.000 & 1.000 & 4089.9 & 30000.0 & 13.6 & B31.3 \\
\hline 38 & 4089.9 & 0.0 & 1.000 & 1.000 & 4089.9 & 30000.0 & 13.6 & B31.3 \\
\hline 38 & 4089.9 & -0.0 & 1.000 & 1.000 & 4089.9 & 30000.0 & 13.6 & B31.3 \\
\hline 39 & 3407.4 & 0.0 & 1.000 & 1.000 & 3407.4 & 30000.0 & 11.4 & B31.3 \\
\hline 39 & 3407.4 & -0.0 & 1.000 & 1.000 & 3407.4 & 30000.0 & 11.4 & B31.3 \\
\hline 40 & 1759.9 & -0.0 & 1.000 & 1.000 & 1759.9 & 30000.0 & 5.9 & B31.3 \\
\hline 40 & 1759.9 & 0.0 & 1.000 & 1.000 & 1759.9 & 30000.0 & 5.9 & B31.3 \\
\hline 50 & 2025.6 & -0.0 & 1.000 & 1.000 & 2025.6 & 30000.0 & 6.8 & B31.3 \\
\hline 50 & 2025.6 & 0.0 & 1.000 & 1.000 & 2025.6 & 35244.5 & 5.7 & B31.3 \\
\hline 60 & 2025.6 & -0.0 & 1.000 & 1.000 & 2025.6 & 34678.0 & 5.8 & B31.3 \\
\hline
\end{tabular}


Data tegangan yang terjadi tiap node akibat temperatur, tekanan dan berat pipa adalah sebagai berikut:

$\begin{array}{lcl}\text { Highest Stresses: (lb./sq.in.) } & \\ \text { Ratio (\%): } & 13.6 & \text { @Node } 30 \\ \text { Code Stress: } & 4089.9 & \text { Allowable Stress: 30000.0 } \\ \text { Axial Stress: } & 376.1 & \text { @Node } 18 \\ \text { Bending Stress: } & 4089.9 & \text { @Node } 30 \\ \text { Torsion Stress: } & 0.0 & \text { @Node } 20 \\ \text { Hoop Stress: } & 0.0 & \text { @Node } 18 \\ \text { Max Stress Intensity: } & 4466.0 & \text { @Node } 30\end{array}$

Perhitungan dengan simulasi Caecar II tegangan yang terjadi sebesar $3761 \mathrm{lb} / \mathrm{in}^{2}$ untuk tegangan axial, tegangan lentur sebesar 4089,9 lb/in ${ }^{2}$ hasil tersebut masih berada di bawah tegangan yang dijinkan sehingga desain pemipaan.

\section{KESIMPULAN}

Loops digunakan dalam sistem pemipaan untuk mencegah terjadinya expansion yang diakibatkan oleh perubahan suhu atau beban dari pipa tersebut. loop akan bergerak secara fleksibel sehingga pipa akan aman dari kegagalan

Setelah melakukan perhitungan untuk merancang dimensi loops maka didapat tingggi loops $(H)=1$ meter, lebar loops $(W)=$ 1 meter dan jarak span 3 meter.
Material pipa dari API $5 \mathrm{~L}$ dengan tegangan yang diijinkan sebesar $30.000 \mathrm{lb} / \mathrm{in}^{2}$, setelah melakukan perhitungan dengan simulasi Caecar II tegangan yang terjadi sebesar 3761 $\mathrm{lb} / \mathrm{in}^{2}$ untuk tegangan axial, tegangan lentur sebesar 4089,9 lb/in ${ }^{2}$ hasil tersebut masih berada di bawah tegangan yang diijinkan sehingga desain pemipaan. Untuk jalur gas ini bisa dikatakan aman, sistem pemipaan ini merujuk kepda Code ASME B31.3.

\section{DAFTAR PUSTAKA}

[1] Armansyah, R., Satrijo, D., Prahasto, T. Desain dan Analisis Tegangan Sistem Perpipaan Main Steam (Low Pressure) pada Combined Cycle Power Plant, Jurnal Teknik Mesin, Vol. 4, No. 2, 2016, 187-196.

[2] ASME B31.3, Process Piping Code Design Requirements, Virtual Training

[3] Lazuardi, B., Kusuma, G.E., Desain Insulasi Expansion loops pada Penggantian Jalur Pipa Transfer Ammonia, PPNS, 2013.

[4] Migas Indonesia.Com Diskusi Konfigurasi Pipa Expansion Loops, 2010.

[5] Kannapan, S. 1986. Introduction to Pipe Stress Analysis. Jhon Wiley And Sons, Inc., U.S.A 
Infomatek Volume 22 Nomor 2 Desember 2020 : 109 - 114

[6] Harahap, S.H. Analisis Pengaruh dan gaya Nozel, BATAN, 2010 Expansion loop pada tegangan pipa 